\title{
Particle size effects of contaminated gravel sand on the leaching of inorganic constituents in column percolation tests
}

\author{
Toru Inui ${ }^{\text {i) }}$, Miyuki Takeo ${ }^{\text {ii) }}$, Atsushi Takai ${ }^{\text {iii) }}$ and Takeshi Katsumi ${ }^{\text {iv) }}$ \\ i) Associate Professor, Graduate School of Global Environmental Studies (GSGES), Kyoto University, Yoshida-honmachi, Sakyo, Kyoto \\ 606-8501, Japan \\ ii) Former Master Student, GSGES, Kyoto University, Yoshida-honmachi, Sakyo, Kyoto 606-8501, Japan \\ iii) Assistant Professor, GSGES, Kyoto University, Yoshida-honmachi, Sakyo, Kyoto 606-8501, Japan \\ iv) Professor, GSGES, Kyoto University, Yoshida-honmachi, Sakyo, Kyoto 606-8501, Japan
}

\begin{abstract}
Applicability of conventional leaching tests is an important issue for characterizing the leaching behavior of coarse-grained soil, since sample preparation including particle size control may affect the testing results. This study investigated the effects of maximum particle size of a sand gravel soil on the leaching behavior of arsenic as well as major cations. Overall, leaching concentrations of these inorganic constituents were higher in the sample containing more fine particles. However, the grading effect on the void ratio of the specimens is influential to the cumulative release since the void ratio affects both the equilibrium concentrations before percolation, as well as the flow velocity during percolation, which was observed in potassium ion release.
\end{abstract}

Keywords: coarse-grained soil, inorganic constituents, leaching, column percolation test

\section{INTRODUCTION}

Soils and rocks contain non-anthropogenic metals and metalloids such as arsenic and lead in relatively low concentrations due to their geologic histories. These metals are fundamentally stable and immobile under the depositional environment. However, once they are excavated in construction works, leaching of these constituents in unacceptable concentrations sometimes occurs by exposure to water and oxygen.

Excavated soils and rocks containing toxic substances, even though they are not anthropogenic, should be properly reused or stored in the ways to prevent adverse environmental impacts. Evaluating the leaching behavior of excavated soils is important for the assessment of environmental risks on surface water and groundwater. Several batch and column leaching tests have been implemented in many countries to determine the concentrations of chemicals of concern $(\mathrm{COCs})$ in water contacting with soils and rocks (e.g. ISO/TS 21268-2 2007, ISO/TS 21268-3 2007). However, applicability of these leaching test methods to rock and coarse-grained soil samples is questionable since samples were usually prepared by crashing and/or sieving into a certain maximum particle size to achieve good test reproducibility for limited mass/volume of samples. Inui et al. (2010) performed several batch leaching tests for rock samples crashed by a certain compaction energy, and concluded that more friable fractions of black shale rock have higher leaching potentials of non-anthropogenic arsenic.

In addition, sample crushing and slaking, which may occur during shaking in the batch test, influence the leaching concentrations. On the other hand, column percolation tests can simulate field conditions in terms of water contact more closely. Also, they allow for the observation of high initial concentrations of percolates at low L/S (Liquid to solid) ratios (equilibrium concentrations) and the time-dependent release of COCs (e.g. Nakamura et al. 2014), although they are more costly and time consuming.

This study aims to investigate the effects of maximum particle size and packing density on the leaching behavior of a sand-gravel soil excavated in tunnel construction works. Leaching profiles of COCs against the percolation volume were compared among the specimens having various maximum particle sizes $(2,4.75$, and $9.5 \mathrm{~mm})$ and void ratios (0.66 to 0.99$)$.

\section{MATERIALS AND METHODS}

\subsection{Materials}

A coarse-grained gravel sand, which was excavated in a shield-tunneling work, was used after sieving with a 19 mm-opening sieve. Figure 1 shows its appearance and particle size distribution curve. The particle density was $2.67 \mathrm{Mg} / \mathrm{m}^{3}$, and the chemical composition determined by an XRF analysis was $\mathrm{SiO}_{2}: 50.1 \%$, 
$\mathrm{Fe}_{2} \mathrm{O}_{3}: 28.4 \%, \mathrm{Al}_{2} \mathrm{O}_{3}: 11.3 \%, \mathrm{~K}_{2} \mathrm{O}: 3.3 \%$ and $\mathrm{CaO}$ : $3.2 \%$. This soil can be classified as GS-F (Gravel sand with fine particles) according to JGS 0051 (2009). It contains non-anthropogenic arsenic with the leaching concentration of $0.016 \mathrm{mg} / \mathrm{L}$, which was determined by Japanese regulatory batch leaching test for soil quality.

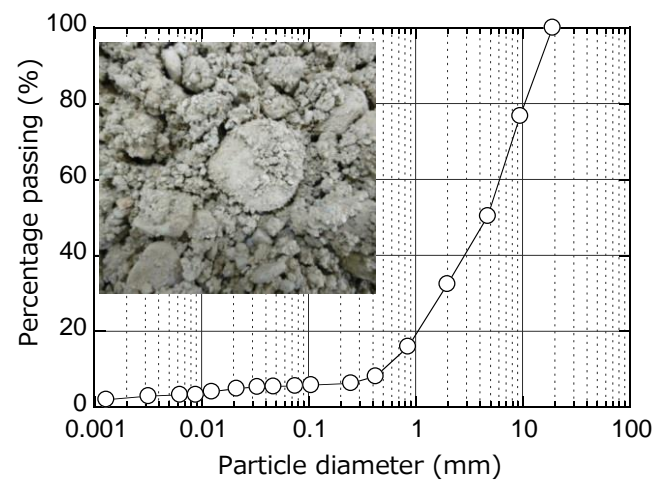

Fig. 1. Particle size distribution curve of the sample.

Batch leaching tests were conducted to evaluate the particle size effect on the leaching potential of the gravel sand sample. The sample was sieved and classified into five fractions in its particle size; 1$)<$ $2 \mathrm{~mm}, 2)<4.75 \mathrm{~mm}$, 3) 2 to $4.75 \mathrm{~mm}$, 4) 4.75 to $9.5 \mathrm{~mm}$, and 5) 9.5 to $19 \mathrm{~mm}$. A conventional batch leaching test was conducted for each fraction Test conditions were shown in Table $1.1 \mathrm{mM} \mathrm{CaCl}_{2}$ solution was used since it was used as the influent in column percolation tests. Immediately after the test, $\mathrm{pH}, \mathrm{Eh}$, and electrical conductivity (EC) were measured for the solution. Afterwards the solutions were filtered using a $0.45-\mu \mathrm{m}$ pore size membrane filter then subjected to analysis for As (arsenic) concentrations using the atomic adsorption spectrometer with the electrothermal atomization system.

Table 1. Testing conditions of the batch leaching test.

\begin{tabular}{l|l}
\hline Solvent & $\begin{array}{l}\text { Distilled water }(\mathrm{pH}=5.8 \text { to } 6.3) \\
\text { and } 1 \mathrm{mM} \mathrm{CaCl}_{2} \text { solution }\end{array}$ \\
Sample dry mass & $>50 \mathrm{~g}$ \\
Liquid to solid ratio & $10 \mathrm{~mL} / \mathrm{g}$-sample \\
Test Duration & 6 hours \\
Mixing & Horizontal shaking at $200 \mathrm{rpm}$ \\
\hline
\end{tabular}

\subsection{Up-flow column percolation test}

The soil was air-dried and then sieved with 2, 4.75 or $9.5 \mathrm{~mm}$-opening sieves to prepare the samples with three different maximum particle sizes. The soil was packed by tamping into an acryl cylindrical column ( $\phi=50 \mathrm{~mm}$ ) up to a height of $300 \mathrm{~mm} \pm 10 \mathrm{~mm}$ with various void ratios. Table 2 summarizes the void ratio and sample mass of each specimen.
Up-flow column percolation tests were conducted according to ISO/TS 21268-3 (2007). Experimental setup of the test is shown in Fig. 2. A plastic plate with holes and a filter paper were placed on the top and bottom side of the column. The bottom side was connected to an influent tank containing $1 \mathrm{mM} \mathrm{CaCl}_{2}$ solution using a Tygon ${ }^{\circledR}$ tube. $1 \mathrm{mM} \mathrm{CaCl}_{2}$ solution was employed to prevent the generation of colloidal substances in percolated water and clogging of the filter papers. Firstly, the specimen was saturated by pumping the influent gradually using a peristaltic pump until the influent reached the top of the column, and then placed for at least 2 days to allow the equilibration of the system. Percolation started with a constant flow rate of $12 \mathrm{~mL} / \mathrm{h}$, which is equivalent to $15 \mathrm{~cm} /$ day in Darcy's velocity. Effluent was collected periodically with its fractions of $0.1 \pm 0.02,0.2 \pm 0.04,0.5 \pm 0.08,1 \pm 0.15$, $2 \pm 0.3,5 \pm 0.4$, and $10 \pm 1 \mathrm{~L} / \mathrm{kg}$ (the ratio of effluent volume to dry mass of the soil). Immediately after the samples were collected, the volume, $\mathrm{pH}, \mathrm{Eh}$, and $\mathrm{EC}$ were measured. Afterwards the samples were filtered using a $0.45-\mu \mathrm{m}$ pore size membrane filter then subjected to analysis for concentrations of water soluble constituents.

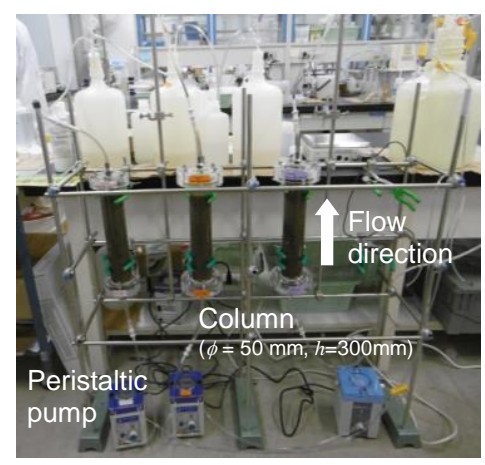

Fig. 2. Up-flow column percolation test.

\section{RESULTS AND DISCUSSIONS}

\subsection{Batch leaching test}

Table 3 presents the results of batch leaching tests. In the Cases $\mathrm{A}$ where the solvent was distilled water, $\mathrm{pH}$ vales were higher for the samples containing $<2$ $\mathrm{mm}$ particles (Cases A1 and A2). This is attributed to a high $\mathrm{pH}$ buffering capacity of fine soil particles. Also, the lower As leaching concentrations and EC values were obtained when the samples contained the less fine particles. These observations confirm that the finer particles of the soil has the higher leaching potentials of As and other water-soluble substances.

When $1 \mathrm{mM} \mathrm{CaCl}_{2}$ solution was adopted, EC values were higher than those obtained in Cases $\mathrm{A}$ by

Table 2. Physical properties of the specimens for up-flow column percolation test.

\begin{tabular}{|c|c|c|c|c|c|c|c|c|c|c|}
\hline \multicolumn{2}{|l|}{ Test case } & S2-1 & S2-2 & S2-3 & S4.75-1 & S4.75-2 & S4.75-3 & S9.5-1 & S9.5-2 & S9.5-3 \\
\hline Maximum particle size & $(\mathrm{mm})$ & & 2.0 & & & 4.75 & & & 9.5 & \\
\hline Dry mass & (g) & 761.0 & 790.7 & 820.3 & 803.6 & 842.7 & 883.2 & 872.5 & 902.3 & 882.0 \\
\hline Void ratio & $(-)$ & 0.99 & 0.94 & 0.83 & 0.91 & 0.80 & 0.78 & 0.77 & 0.70 & 0.66 \\
\hline
\end{tabular}


approximately $15 \mathrm{mS} / \mathrm{m}$, which was equivalent to the baseline $\mathrm{EC}$ of $1 \mathrm{mM} \mathrm{CaCl}$ solution. This indicates that the use of $1 \mathrm{mM} \mathrm{CaCl}_{2}$ solution did not affect the overall leaching concentrations of chemicals. However, As concentrations were drastically decreased, because the use of $1 \mathrm{mM} \mathrm{CaCl}$ solution lowered the concentrations of colloids in the solution and accordingly arsenic attached to the colloids were not detected in the analysis.

Table 3. Results of batch leaching tests.

\begin{tabular}{cccccc}
\hline Case & Fractions & Solvent & $\begin{array}{c}\text { As. conc. } \\
(\mathrm{mg} / \mathrm{L})\end{array}$ & $\begin{array}{c}\mathrm{EC} \\
(\mathrm{mS} / \mathrm{m})\end{array}$ & $\mathrm{pH}$ \\
\hline $\mathrm{A} 1$ & $<2 \mathrm{~mm}$ & & 0.016 & 6.07 & 7.55 \\
$\mathrm{~A} 2$ & $<4.75 \mathrm{~mm}$ & Distilled & 0.020 & 4.29 & 7.61 \\
$\mathrm{~A} 3$ & $2-4.75 \mathrm{~mm}$ & water & 0.016 & 3.48 & 6.31 \\
$\mathrm{~A} 4$ & $4.75-9.5 \mathrm{~mm}$ & & 0.015 & 2.46 & 6.88 \\
$\mathrm{~A} 5$ & $9.5-19 \mathrm{~mm}$ & & 0.010 & 2.02 & 6.98 \\
$-\mathrm{B} 1$ & $<2 \mathrm{~mm}$ & & 0.002 & 21.5 & 6.86 \\
$\mathrm{~B} 2$ & $<4.75 \mathrm{~mm}$ & $1 \mathrm{mmol} / \mathrm{L}$ & N.D. & 24.6 & 6.92 \\
$\mathrm{~B} 3$ & $2-4.75 \mathrm{~mm}$ & $\mathrm{CaCl}_{2}$ & 0.002 & 20.04 & 6.79 \\
$\mathrm{~B} 4$ & $4.75-9.5 \mathrm{~mm}$ & solution & N.D. & 16.60 & 6.90 \\
$\mathrm{~B} 5$ & $9.5-19 \mathrm{~mm}$ & & N.D. & 17.78 & 7.18 \\
\hline
\end{tabular}

\subsection{Column percolation test}

Figures 3 shows EC changes with the cumulative flow volume normalized by the pore volume of each specimen (PVF: pore volumes of flow) for the fractions of $<2 \mathrm{~mm}$ and $<9.5 \mathrm{~mm}$. Until the PVF reached 1, the pore water retained in the first 2 days equilibration period was drained. Overall, the specimens with the smaller void ratio gave the higher EC values regardless of the maximum particle size. Particularly, the higher EC values were observed in the fraction of $<9.5 \mathrm{~mm}$, which was well-graded and subjected to the smaller void ratio when the specimen was prepared by tamping, comparing with the fraction of $<2 \mathrm{~mm}$. The smaller void ratio led to the higher EC values during the equilibration period before percolation, since the liquid volume was relatively small in the whole system.

After the PVF reached around 4, the EC values were almost stable (residual state). However, this residual EC values were higher for the fraction of $<2 \mathrm{~mm}$, even noting that the absolute flow volume at a certain PVF was larger for the fraction of $<2 \mathrm{~mm}$ with the larger void ratio than that of the fraction of $<9.5 \mathrm{~mm}$. This trend is consistent to the batch test result that the higher EC values were obtained when the samples contained more fine particles.

Figures 4 shows $\mathrm{pH}$ changes with the PVF. $\mathrm{pH}$ values were gradually decreasing from the initial equilibrium pH. Particularly, the fraction of $<9.5 \mathrm{~mm}$ with the smaller void ratio had a clearer decreasing trend, since the flow velocity was relatively higher. These observations on EC and $\mathrm{pH}$ profiles indicated that the maximum particle size and grading of the sample led to the variation in packing density, and accordingly $\mathrm{pH}$ and $\mathrm{EC}$ profiles were influenced.

Figures 5, 6 and 7 presents the cumulative release of As and major cations ( $\mathrm{Na}, \mathrm{K}$, and $\mathrm{Mg}$ ions) with the cumulative flow volume, represented by the L/S (liquid to the solid ratio). Similar to the batch leaching tests using $1 \mathrm{mM} \mathrm{CaCl}{ }_{2}$ solution, As leaching mass was very

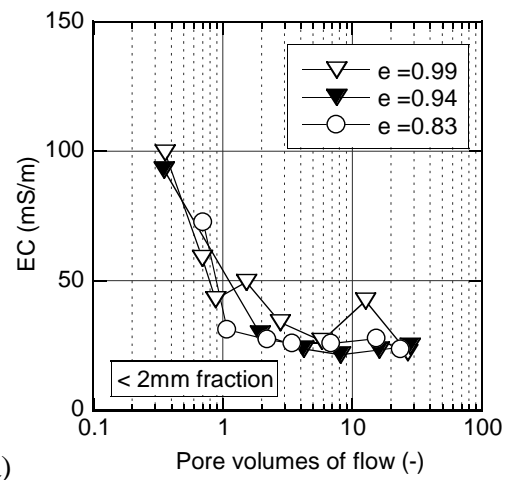

(a)

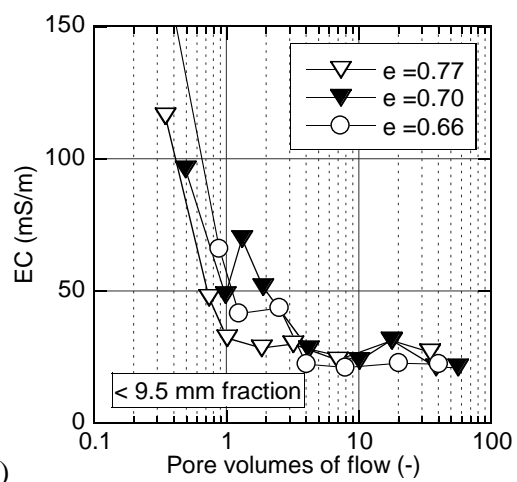

Fig. 3. EC profiles in the column tests: (a) $<2 \mathrm{~mm}$ fraction and (b) $<9.5 \mathrm{~mm}$ fraction.
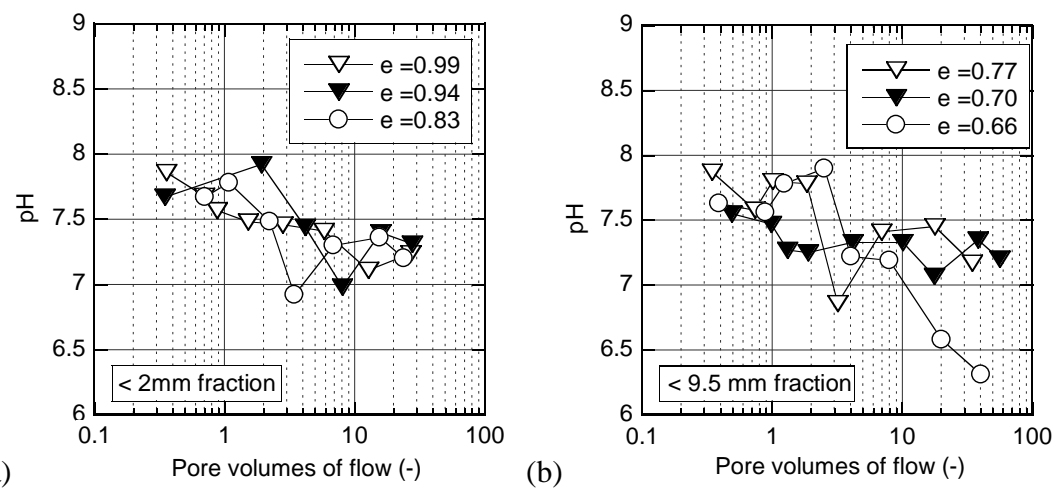

Fig. 4. $\mathrm{pH}$ profiles in the column tests: (a) $<2 \mathrm{~mm}$ fraction and (b) $<9.5 \mathrm{~mm}$ fraction.

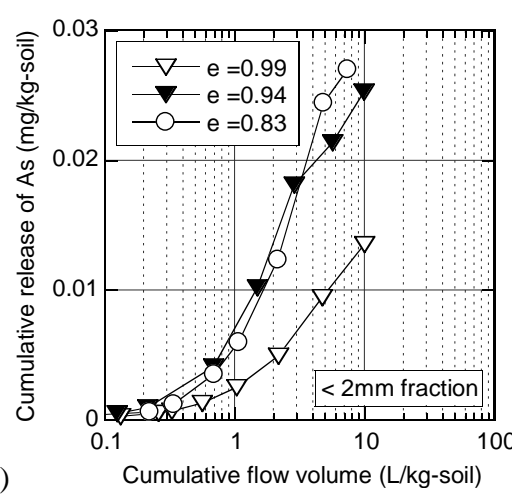

(a)

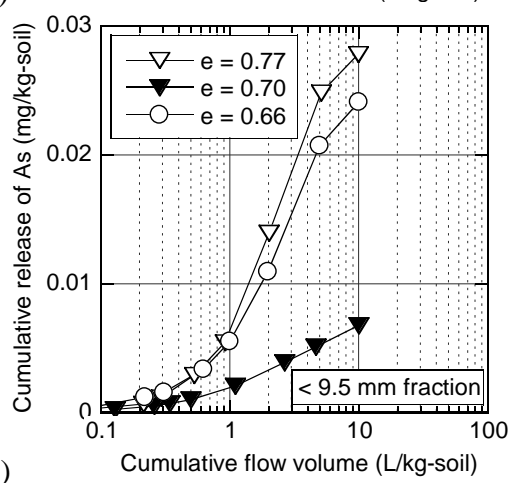

Fig. 5. Cumulative release of As in the column percolation tests: (a) $<2 \mathrm{~mm}$ fraction and (b) $<9.5 \mathrm{~mm}$ fraction. 

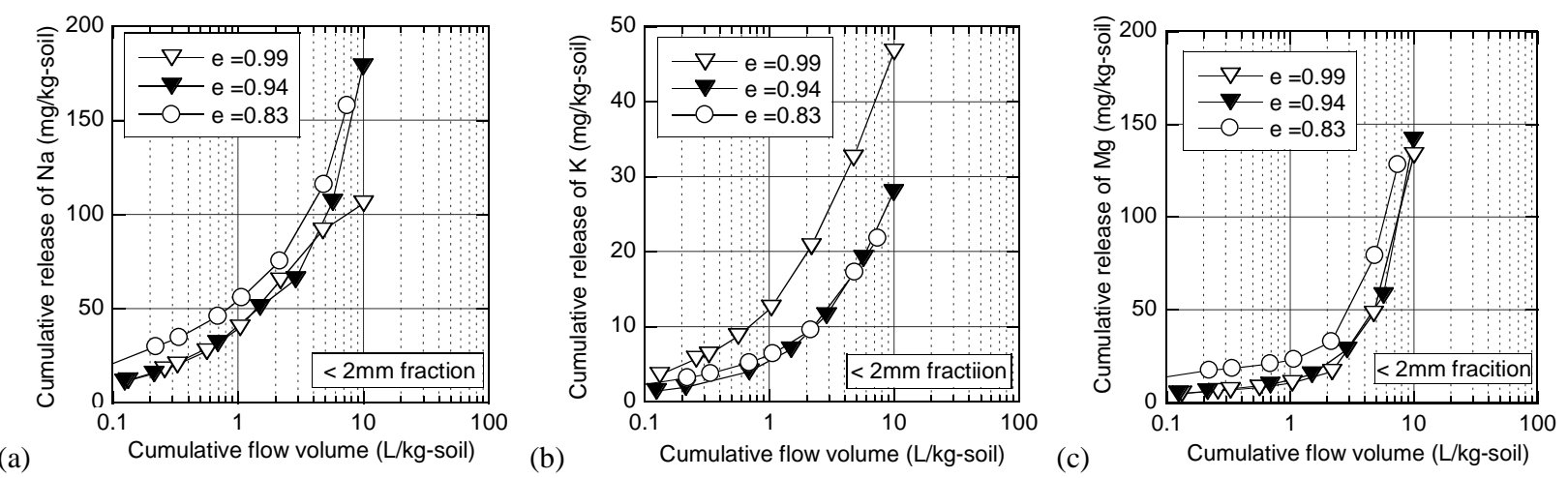

Fig. 6. Results of the column percolation test for $<2 \mathrm{~mm}$ fraction: (a) sodium ions, (b) potassium ions, and (c) magnesium ions.
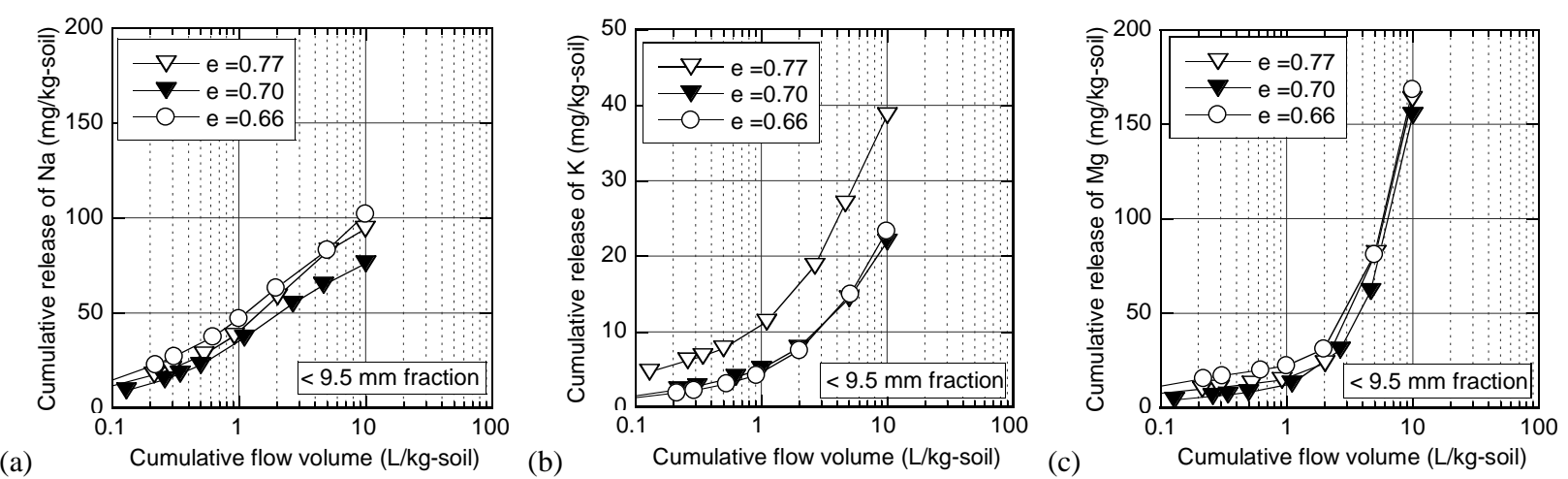

Fig. 7. Results of the column percolation test for $<9.5 \mathrm{~mm}$ fraction: (a) sodium ions, (b) potassium ions, and (c) magnesium ions.

small, and test reproducibility among similar testing conditions was not good as shown in Fig. 5.

For $\mathrm{Na}$ and $\mathrm{K}$ ions, as the percolation progressed, the leaching concentrations decreased more significantly for the specimens with less fine particles, such as the fractions of $<4.75 \mathrm{~mm}$ and $<9.5 \mathrm{~mm}$. Cumulative release of these cations were accordingly largest in the fraction of $<2 \mathrm{~mm}$. However, no grain size effect was observed in the cumulative release of $\mathrm{Mg}$. Considering the void ratio effect, the smaller void ratio gave the more release of $\mathrm{Na}$ and $\mathrm{Mg}$ ions, the leaching concentrations of which were much higher than others, at a certain L/S. This trend is well consistent with that of EC values shown in Fig. 3. Contrary to this trend, the release of $\mathrm{K}$ ion was largest when the void ratio was largest regardless of the fractions. These observations indicates that effects of density and particle size on the leaching behaviors of inorganic constituents are attributed to both the initial equilibrium condition before percolation and the effect of flow velocity, which is determined by the void ratio.

\section{CONCLUSIONS}

This study addresses the effects of maximum particle size of the coarse-grained soil sample on the leaching behavior. Overall, leaching concentrations of COCs according to the percolation volume were higher in the sample containing more fine particles. However, the grading effect on the void ratio of the specimens is influential to the cumulative release since the void ratio affects both the equilibrium conditions before percolation and the flow velocity during percolation.

\section{ACKNOWLEDGEMENTS}

This research was supported by JSPS KAKENHI Grant Number 15H02264 and 25289145. The authors would like to acknowledge Dr. Hirofumi Sakanakura (National Institute for Environmental Studies, Japan) and Dr. Tetsuo Yasutaka (Advanced Industrial Science and Technology, Japan) for their valuable support.

\section{REFERENCES}

1) Inui, T., Katsumi, T., Katayama, M. and Kamon, M. (2010): Effects of friability and grain size on the leaching of heavy metals in excavated rock materials, Environmental Geotechnics for Sustainable Development, M. Datta et al. (eds.), Tata McGraw Hill, New Delhi, pp.730-733.

2) ISO/TS 21268-2 (2007): Soil quality - Leaching procedures for subsequent chemical and ecotoxicological testing of soil and soil materials - Part 2: Batch test using a liquid to solid ratio of $10 \mathrm{~L} / \mathrm{kg}$ dry matter, ISO.

3) ISO/TS 21268-3 (2007): Soil quality - Leaching procedures for subsequent chemical and ecotoxicological testing of soil and soil materials - Part 3: Up-flow percolation test, in, ISO.

4) JGS 0015 (2009): Method of classification of geomaterials for engineering purposes, Japanese Geotechnical Society.

5) Nakamura, K., Yasutaka, T., Fujikawa, T., Takeo, M., Sato, K., Watanabe, Y., Inoba, S., Tamoto, S., and Sakanakura, H. (2014): Up-flow column tests to evaluate heavy metal leaching for standardization, Japanese Geotechnical Journal, 9(4), pp.697-706. 